\title{
Microstructure and precipitates in thick-walled X90 bend related to mechanical properties
}

\author{
Liang Wang ${ }^{1}$, Bin Wang ${ }^{2}$, YIwen $\mathrm{Hu}^{1}$, Juan $\mathrm{Li}^{1}$, and Shimei Tao ${ }^{1}$ \\ ${ }^{1}$ Affiliation not available \\ ${ }^{2}$ Southwest Petroleum University
}

May 21, 2020

\begin{abstract}
The microstructure and precipitate characterizes in the API X90 hot bend related to mechanical properties was investigated by OM, TEM, EBSD and mechanical tests. X90 pipeline steel is consist of quasi-polygonal ferrite (QPF), acicular ferrite (AF), lath bainite (LB) and a small amount of M/A constituents. The width of bainite lath is about $0.2 \sim 0.3 \mu \mathrm{m}$. After hot induction bending, hardly observe AF in the bend zone. In the outer arc side, the width of LB was coarsened to $0.53 \sim 1.34 \mu \mathrm{m}$, and sharp $\mathrm{M} / \mathrm{A}$ constituents formed along the prior austenite grain boundaries. Compared to the parent pipe, the strength of X90 bend decreased $30 \sim 80 \mathrm{MPa}$, and the Charpy impact energy increased $20 \mathrm{~J}$. The outer arc side with the weakest low temperature impact toughness, is $153 \mathrm{~J}$. The main component of the precipitate is $\mathrm{NbC}$ with a small amount of $\mathrm{TiC}, \mathrm{possibly}(\mathrm{Ti}, \mathrm{Nb}) \mathrm{C}$, and the size is about $15 \mathrm{~nm}$. The fraction of the high angle grain boundaries (HAGBs) and the kernel average misorientation (KAM) value of the outer arc side is $21 \%$ and $0.62^{\circ}$ respectively, which is the higher than the other positions.
\end{abstract}

\begin{abstract}
The microstructure and precipitate characterizes in the API X90 hot bend related to mechanical properties was investigated by OM, TEM, EBSD and mechanical tests. X90 pipeline steel is consist of quasi-polygonal ferrite (QPF), acicular ferrite (AF), lath bainite (LB) and a small amount of M/A constituents. The width of bainite lath is about $0.2^{\sim} 0.3 \mu \mathrm{m}$. After hot induction bending, hardly observe AF in the bend zone. In the outer arc side, the width of LB was coarsened to $0.53 \sim 1.34 \mu \mathrm{m}$, and sharp M/A constituents formed along the prior austenite grain boundaries. Compared to the parent pipe, the strength of X90 bend decreased $30^{\sim}$ $80 \mathrm{MPa}$, and the Charpy impact energy increased $20 \mathrm{~J}$. The outer arc side with the weakest low temperature impact toughness, is $153 \mathrm{~J}$. The main component of the precipitate is $\mathrm{NbC}$ with a small amount of TiC, possibly $(\mathrm{Ti}, \mathrm{Nb}) \mathrm{C}$, and the size is about $15 \mathrm{~nm}$. The fraction of the high angle grain boundaries (HAGBs) and the kernel average misorientation (KAM) value of the outer arc side is $21 \%$ and $0.62^{\circ}$ respectively, which is the higher than the other positions.
\end{abstract}

Keywords:X90; hot induction bending; microstructure; TEM; EBSD

Introduction

To increase transportation efficiency, high strength thick-walled pipeline steels are used to transport the crude oil and natural gas under high press. However, high strength is generally achieved at the expense of reduced toughness and ductility. Low carbon and rich microalloying design is preferred because of excellent lowtemperature impact toughness and high strength combination [1-3]. To achieve an improvement of strength and toughness combination, thermos-mechanical control processing (TMCP) is the common way and grain refinement plays an important role [4-7]. API (American Petroleum Institute) X70 and X80 grade steels are achieved by TMCP development rapidly, and employed in the field of high pressure, large diameter, long distance transportation. However, API X90 X120 pipeline steel as the next generation of pipelines has 
been researched to enhance the strength in the future. The bends with large wall thickness and high strength grade, not only change the direction of pipeline transportation in accordance with the terrain requirements, but also buffer the tensile, compressive stress and torsion attach to the pipeline because of ground movement, earthquakes and environmental temperature changes [8-9].

For the pipeline steel in service, microalloying design and TMCP parameters changing promoted the excellent mechanical properties. Addition of microalloyed elements $\mathrm{Ti}, \mathrm{V}, \mathrm{Nb}$ form fine carbide and carbonitride precipitates, which dispersed uniform sufficiently to achieve precipitation strengthening and refine the grains effectively [10]. Literatures [11-13] reported that the precipitation behavior and the relationship to mechanical properties of low carbon microalloyed steels during TMCP schedule. However, the manufacture of thickwalled large-diameter bends is mostly carried out by hot induction bending, which with the double effect of re-heating and deformation affecting the original microstructure and mechanical properties, especially the thick-walled pipeline steels were obtained by the TMCP process. In general, bending parameters would seriously affect the performance of the bend, such as the re-heating temperature, push speed, cooling water flow, tempering temperature. The re-heating temperature is order to austenitizing the microstructure that can be plastic deformed under the pushing force. Therefore, the heating temperature is higher than the austenite phase transition temperature, in the range of $950^{\sim} 1050{ }^{\circ} \mathrm{C}[14-18]$. Microstructure transformation, fine carbide (or carbonitride) precipitates dissolving and redistribution causing an unstable factor during the hot induction bending process [19].

The high-strength pipeline steel is easily obtained the complex microstructure of acicular ferrite(AF) (or bainite ferrite(BF)), granular bainite(GB) and martensite/austentite (M/A) constituents after hot induction bending [15-18]. Only a part of carbide (or carbonitride) precipitations formed by microalloying elements $\mathrm{Ti}$, $\mathrm{V}, \mathrm{Nb}$ dissolved. The precipitations are benefit for prevent grain boundary moving to prevent grain growth significantly. In addition, the microstructure almost distributed with different orientation, and a large number of dislocations existed in fine grains. The composite microstructure of AF and GB ensures that the bend with a good toughness, but the plasticity and large strain resistance is difficult to reach the level of the parent pipeline steel $[17,18]$. Many literatures [18, 20,21] investigated the hot induction bend were focus on the effects of hot bending parameters on microstructure and mechanical properties, and the relationship of microstructure and mechanical properties through thermal simulation tests. However, the deformation in the bending process was not take into account. The research about the microstructure and mechanical properties changes in the bend zone still has a lot work waiting to be completed.

The hot induction bending process for API X70, X80 pipeline steel has been studied maturely, especially the effect on the microstructure and mechanical properties, but the research on API X90 hot bending process has not been completed. It is therefore the main objective of this paper to address the microstructure and precipitate in the bend zone of thick-walled API X90 pipeline steel related to mechanical properties. The evolution of microstructure, precipitation distribution, grain boundaries distribution, local strain distribution and mechanical properties in API X90 bend are established.

Experimental procedure

The material in the study for investigation is submerged arc welded API X90 grade pipeline steel with $\Phi 1219$ $\mathrm{mm} \times 26.4 \mathrm{~mm}$. The chemical components are listed in Table 1 . The experimental steel is low in carbon content and rich microalloying elements with contains $0.065 \% \mathrm{C}, 1.82 \% \mathrm{Mn}, 0.43 \% \mathrm{Mo}$, and $\mathrm{Nb}+\mathrm{V}+\mathrm{Ti}$ less than $0.1 \%$. The relatively low carbon content ensures good weldablity, toughness and ductility. The role of small amount of $\mathrm{Ti}$ was to tie-up nitrogen and limit grain growth, while microalloying element $\mathrm{Nb}$ facilitates grain refinement and provides strengthening via precipitation as $\mathrm{NbC}$ in the ferrite matrix and on the dislocations [22]. Element boron addition reduced $A_{r 3}$ and $A_{r 1}$ temperature about 100 that can produce bainitic ferrite and martensite, and effectively suppress pearlite and ferrite formation that revealed the increase of hardness related to tensile strength [23]. Microalloying elements $\mathrm{Cu}, \mathrm{Ni}, \mathrm{Cr}$ are added to promote the corrosion resistance.

Table 1 Chemical components of X90 pipeline steel (wt.\%). 


\begin{tabular}{lllllllllllll}
\hline Elements & $\mathrm{C}$ & $\mathrm{Mn}$ & $\mathrm{Si}$ & $\mathrm{Nb}$ & $\mathrm{V}$ & $\mathrm{Ti}$ & $\mathrm{Cr}$ & $\mathrm{Mo}$ & $\mathrm{Cu}$ & $\mathrm{Ni}$ & $\mathrm{B}$ & $\mathrm{Fe}$ \\
\hline & 0.065 & 1.82 & 0.281 & 0.044 & 0.018 & 0.013 & 0.022 & 0.426 & 0.148 & 0.375 & 0.0007 & Balance \\
\hline
\end{tabular}

$\mathrm{CEV}=\mathrm{C}+\mathrm{Si} / 30+(\mathrm{Mn}+\mathrm{Cu}+\mathrm{Cr}) / 20+\mathrm{Ni} / 60+\mathrm{Mo} / 15+\mathrm{V} / 10+5 \mathrm{~B}=0.21$

The API X90 was bended at 1000 with the bend angle of $7^{\circ}$, and then tempered at 560 . It is noticed that water cooling online at the same time during the bending process, the detailed hot induction bending parameters shown in Table 2. The bending process and the position of neutral axis and weld joint is shown in Fig.1.

Table 2 Hot induction bending parameters of X90 pipeline steel.

\begin{tabular}{lllllll}
\hline $\begin{array}{l}\text { Heating } \\
\text { temperature }()\end{array}$ & $\begin{array}{l}\text { Push speed } \\
(\mathrm{mm} / \mathrm{min})\end{array}$ & $\begin{array}{l}\text { Cooling water } \\
\text { flow }\left(\mathrm{m}^{3} / \mathrm{h}\right)\end{array}$ & $\begin{array}{l}\text { Bending angle } \\
\left({ }^{\circ}\right)\end{array}$ & $\begin{array}{l}\text { Tempering } \\
\text { temperature }()\end{array}$ & $\begin{array}{l}\text { Holding time } \\
(\mathrm{min})\end{array}$ & Cooling \\
1000 & 25 & 44 & 7 & 560 & 70 & Air Cooling \\
\hline
\end{tabular}

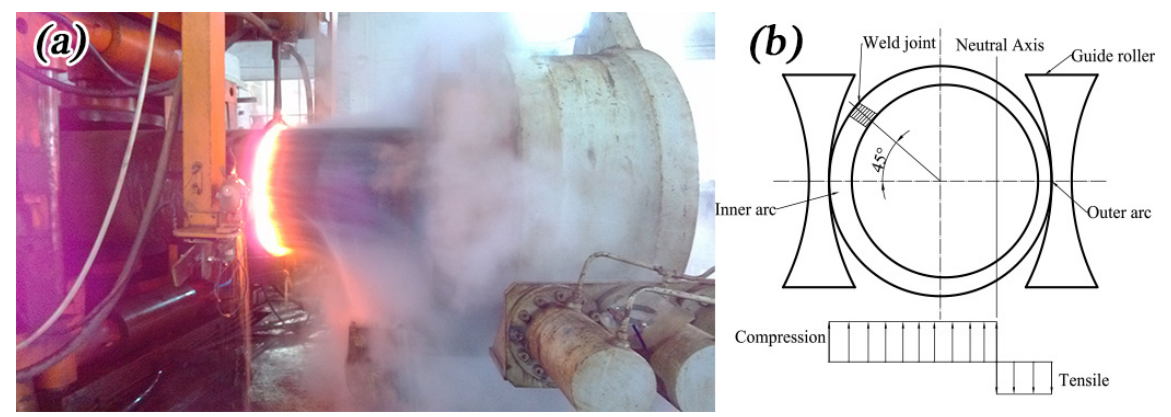

Fig.1. The hot pipe bending process using local induction heating: (a) Pipe bending; (b) Position of neutral axis and weld joint.

Samples for mechanical tests were cut at different positions in X90 bend, as shown in Fig.2. Tensile specimens were machined into flat of $50 \mathrm{~mm}$ gauge length according to ASTM E8M specification. The tensile tests were performed at room temperature using a low loading speed of $3 \mathrm{~mm} / \mathrm{min}$ on SHT 4605 testing machine. CVN impact tests were performed on standard samples with $55 \mathrm{~mm} \times 10 \mathrm{~mm} \times 10 \mathrm{~mm}$ according to ASTM standard E23. The $\mathrm{V}$ notch parallel to the normal direction, three parallel specimens were taken at -10 , and the average value of the absorbed energy was obtained as the result of the impact test. The impact toughness was tested on a 500J instrumented pendulum impact tester. Considering the temperature of specimens increase in the process of transfer, and the specimens were cooled to below the test temperature 5 . 


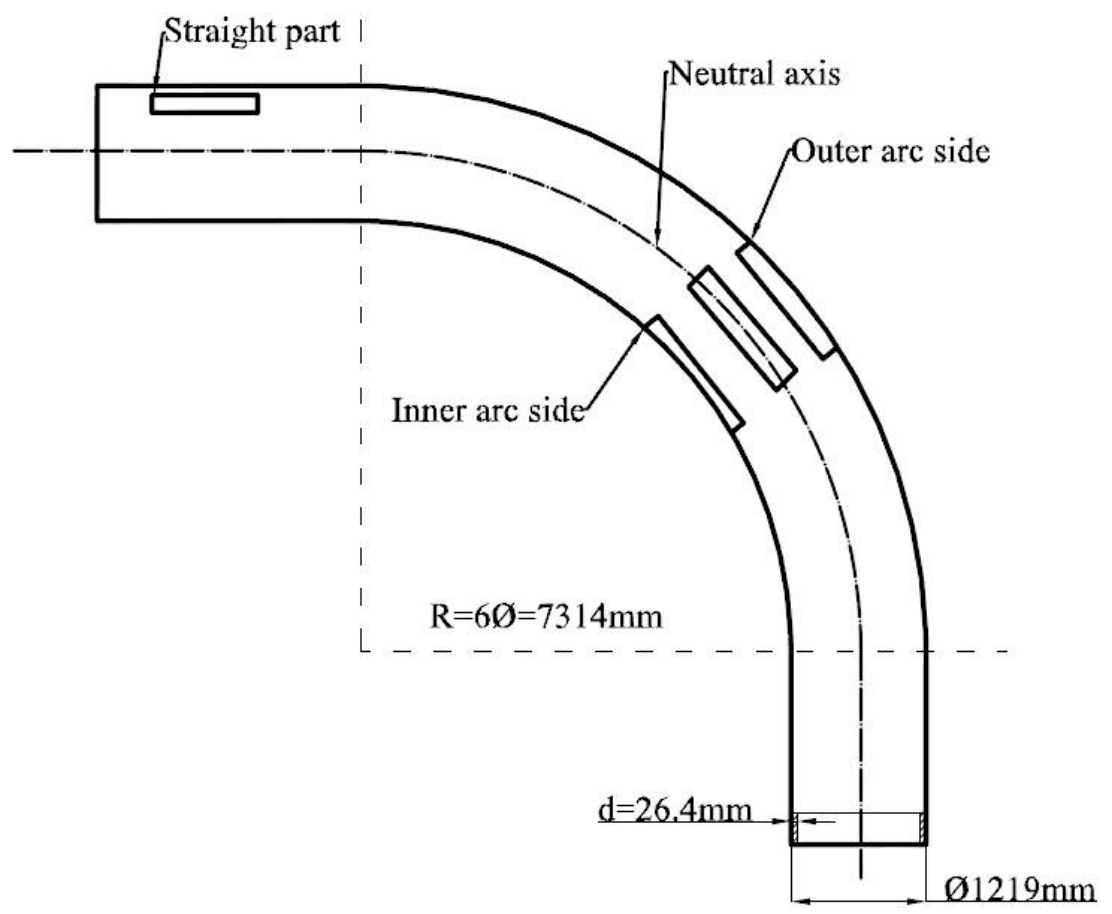

Fig.2. Schematic illustration of different positions of X90 bend.

To investigate the microstructure characterizes, small samples were cut from the pipe part. Standard grinding and polishing technique were employed to obtain mirror surface. Then, the polished surface was etched with a solution of 4 vol.\% natal to reveal the microstructure via Leica DMIRM optical microscope (OM) and JSM-5900LV scanning electron microscopy (SEM). Transmission electron microscopy (TEM) was carried out to identify the phase composition, and examine the dislocation distribution. The TEM foils were cut from the samples, mechanical grinding to about $50 \mu \mathrm{m}$ thickness. $3 \mathrm{~mm}$ disks were punched from the foils and twin-jet electropolished with a solution of $75 \%$ methanol $+25 \%$ nitric acid as electrolyte at -30 . Foils were examined with a JEOL2010 TEM operated at $200 \mathrm{kV}$.

Electron back-scatter diffraction (EBSD) analysis was performed on a FEI NANO SEM 430 field-emission scanning electron micro-scope (FE-SEM) in order to study the grain boundaries and local misorientation. Local misorientation was used to evaluate small strain gradients in material. The data were post-processed with Channel 5 software provided by Oxford HKL Technology ${ }^{\circledR}$. The specimens were electrolytically polished a solution of $650 \mathrm{ml}$ alcohol, $100 \mathrm{ml}$ chlorate, and $50 \mathrm{ml}$ distilled water at room temperature for $20 \mathrm{~s}$. The EBSD maps were obtained using a step size of $0.15 \mu \mathrm{m}$, area over $60 \mu \mathrm{m} \times 60 \mu \mathrm{m}$.

Results and discussion

\subsection{Mechanical properties}

The mechanical properties of the experimental bend are shown in Table 3. The results revealed that there is difference in mechanical properties between X90 parent pipe and the bend. The yield strength and tensile strength of the parent pipe is $748 \mathrm{MPa}$ and $847 \mathrm{MPa}$, respectively. The strength of X90 bend decreased $30^{\sim}$ $80 \mathrm{MPa}$ compared with the parent pipe, but the plasticity and toughness improved. According to the data in Table 3, different positions in the X90 bend reflected the different mechanical properties. The yield and tensile strength in the outer arc side is $750 \mathrm{MPa}$ and $848 \mathrm{MPa}$, respectively. The elongation is $21 \%$. The yield strength, tensile strength in the inner arc side and the neutral axis is lower about $50 \mathrm{MPa}$ than that of outer arc side. However, the impact toughness at -10 of outer arc side is the weakest in X90 bend, the impact absorbed energy is $153 \mathrm{~J}$, and the energy of other positions is more than $200 \mathrm{~J}$ that is larger than 
that of the parent pipe. During hot induction bending, the outer arc side was subjected the effect of tensile stress and heat treatment. Therefore, the position with a high strength and low toughness. Moreover, there is no effect of deformation on the position of neutral axis, and with the same mechanical properties of the straight part.

Table 3 Tensile and Charpy impact properties of the bend.

\begin{tabular}{|c|c|c|c|c|c|}
\hline Specimens & $\begin{array}{l}\text { Yield strength } \\
\mathrm{Rt}_{0.5}(\mathrm{MPa})\end{array}$ & $\begin{array}{l}\text { Tensile strength } \\
\mathrm{Rm}(\mathrm{MPa})\end{array}$ & $\begin{array}{l}\text { Elongation } \\
\text { A50mm(\%) }\end{array}$ & $\begin{array}{l}\text { Yield ratio } \\
\mathrm{Rt}_{0.5} / \mathrm{Rm}\end{array}$ & $\begin{array}{l}\text { Impact absorbed } \\
\text { energy at }-10(\mathrm{~J})\end{array}$ \\
\hline $\begin{array}{l}\text { X90 Parent } \\
\text { pipe }\end{array}$ & 748 & 847 & 17.5 & 0.90 & 204 \\
\hline Straight part & 710 & 821 & 20 & 0.86 & 223 \\
\hline Inner arc side & 706 & 802 & 24 & 0.88 & 225 \\
\hline Outer arc side & 750 & 848 & 21 & 0.88 & 153 \\
\hline $\begin{array}{l}\text { The neutral } \\
\text { axis }\end{array}$ & 693 & 785 & 22 & 0.88 & 220 \\
\hline
\end{tabular}

\subsection{Microstructure investigation}

The microstructure of the experimental steel is shown in Fig.3(a, b). Due to a large number of substructures and dislocations generated in the deformed prior austenite grains during controlling and rolling process, fine final microstructure was promoted effectively. In addition, recrystallization of deformed austenite and the precipitates of $\mathrm{Nb}, \mathrm{Ti}, \mathrm{V}$ micro-alloying elements pining grain boundaries also promote the fine grains. According to Fig.3(a, b), X90 pipeline steel is a multiphase structure composed of quasi-polygonal ferrite (QPF), acicular ferrite (AF), lath bainite (LB) and a small amount of M/A constituent which is a mixture of martensite and retained austenite. Ferrite and bainite distributed evenly, M/A constituent dispersed on the grain boundaries and matrix in the form of granular or elongated, which is bright white under SEM, as shown in Fig.3 (b) by the arrows. The morphology and nucleation mechanism of QPF is different from that of AF. The coarse QPF is referred to as 'proeutectoid ferrite' formed at a lower temperature, and the latter is closed to Widmanstätten ferrite [24]. AF is slender and clutter than QPF, as shown in Fig. 3(a). M/A constituents in LB are in the form of long or short rods, and distributed in parallel. LB is the primary microstructure increasing the strength of X90 pipeline steel, and the consequent of LB enhancement is deeply depend on the total amount of M/A constituents. The strength increased with the number of M/A constituents increasing. The impact toughness is excellent when M/A constituent is finer and dispersed evenly [25]. In the TMCP process, substructures, dislocations and the increasing grain boundaries in the prior refinement austenite grains that could be used as nucleation sites of LB. As a consequence, the final microstructure composed of a number of fine LB. In general, M/A constituent as the brittle phase is possibly be the cracks initiation. The shape, size and distribution affecting the toughness effectively. Chunming Wang [25] proved that the yield strength of the material increasing with the increase of M/A constituents, but destroyed the continuity of the matrix. it will reduce the low temperature toughness when the M/A constituent is large in size and with angular.

After hot induction bending, the X90 bend has a relatively large size grain compared with the parent pipe. The same heat treatment process on the straight part and the bending zone, quenching and high temperature tempering. However, the outer arc side and inner arc side was subjected the maximum tensile and pressure tress according to the bending force during forming process. According to Fig. 3, the microstructure of the straight part is composed of polygonal ferrite (PF) and granular bainite (GB), as shown in Fig. 3(c, d). M/A constituents in GB are spherically distributed on the matrix or between the laths. The neutral axis has the same microstructure with the straight part because of only a little deformation in the positions, as shown in Fig. $3(i, j)$. It can be found that there are some black clusters at the grain boundaries, which are the decomposition products of the retained austenite during the tempering process. There are many discontinuous carbides between bainite laths. In addition, some black carbide particles are found on the bainite and ferrite 
matrix. The microstructure of other positions in the bend zone is quite different, especially in the inner arc side and outer arc side. The bend zone was subjected the double effecting of deformation and heat treatment, the microstructure is consisted of PF and a large number of LB in the outer arc side. The microstructure is consisted of GB, LB and PF in the inner arc side, hardly observe AF in the bend zine. The prior austenite grain boundaries are clearly visible in the inner arc side and outer arc side, some point-like M/A constituents are distributed on the grain boundaries, as shown in Fig. 3(c-f). When the X90 parent pipe was reheated to austenitizing tempertaure, the fine PF was produced after quenching because of dynamic strain induced transformation (DSIT). When the temperature reached to the martensite start transformation temperature, a small portion of retained austenite transformed into martensite, forming M/A constituents [1]. The bainite

laths are almost parallel, long and thin, which help improving toughness while increasing strength. Some of the carbides precipitation and the bainite grain boundaries became blurred after high temperature tempering. 

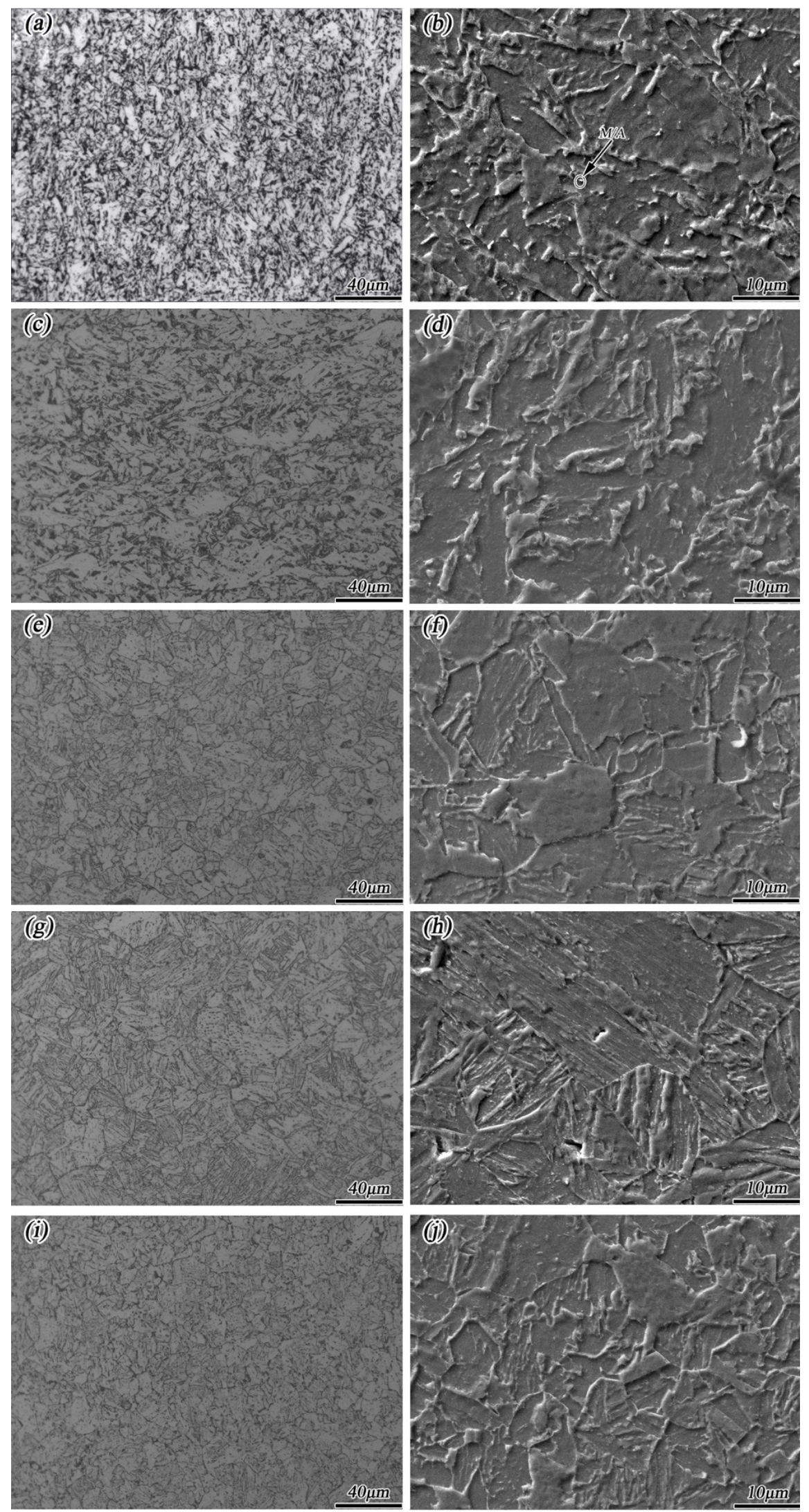
Fig.3 Optical and SEM micrographs of experimental steel at different positions: (a) OM of X90 parent pipe; (b) SEM of X90 parent pipe; (c) OM of the straight part; (d) SEM of the straight part; (e) OM of the inner arc side; (f) SEM of the inner arc side; (g) OM of the outer arc side; (h) SEM of the outer arc side; (i) OM of the neutral axis position; (j) SEM of the neutral axis position.

Transmission electron microscopy (TEM) was used to investigate the microstructure further. A large number of dislocations in the QPF matrix, and the density of dislocations near the grain boundaries is higher than that of within QPF, as shown in Fig. 4(a). Moreover, some dislocation cells and substructures piled up the grain boundaries. It is generally believed that there is a number of sub-structures in the QPF and AF grains during the rolling process of TMCP because of shear transformation [26]. Two kinds of microstructure around the QPF, the one is fine AF with the width of about $300 \mathrm{~nm}$, and the other is M/A constituent distributed on the grain boundaries. Because of the diffusion speed of carbon atoms into non-transformation austenite after QPF nucleation decreased significantly, and some fine cementite was found in the grain, as shown in Fig. 4(a). LB is arranged in parallel by a number of laths with a width of about $200 \mathrm{~nm}$ to $300 \mathrm{~nm}$, and with a very large aspect ratio. As shown in Fig. 4(b), these laths are clear and straight, some elongated hard phase M/A constituents existed between the laths. The grain boundaries between the laths are low angle grain boundaries (LAGBs) and the boundaries of laths are high angle grain boundaries (HAGBs) [27]. Compared to QPF shown in Fig. 4(a), dislocations intertwined together in LB grain that could hinder further improve the strength. AF as shown in Fig. 4(b), non-parallel laths with different orientation were observed under TEM and a large number of dislocations in the matrix. These AF arranged disorderly and engaged each other to improve the strength. From Fig. 4(c), it is obviously that fine M/A constituents distributed between the QPF grain boundaries and the AF laths. The mixture microstructure of $\mathrm{AF}$ and dispersion distributed M/A constituents could effectively hinder crack propagation to improve the low temperature impact toughness. The typical shape of M/A constituents is oval as shown in Fig. 4(d), the oval shape of M/A constituents would not produce stress concentration to avoid promote crack initiation and propagation. 

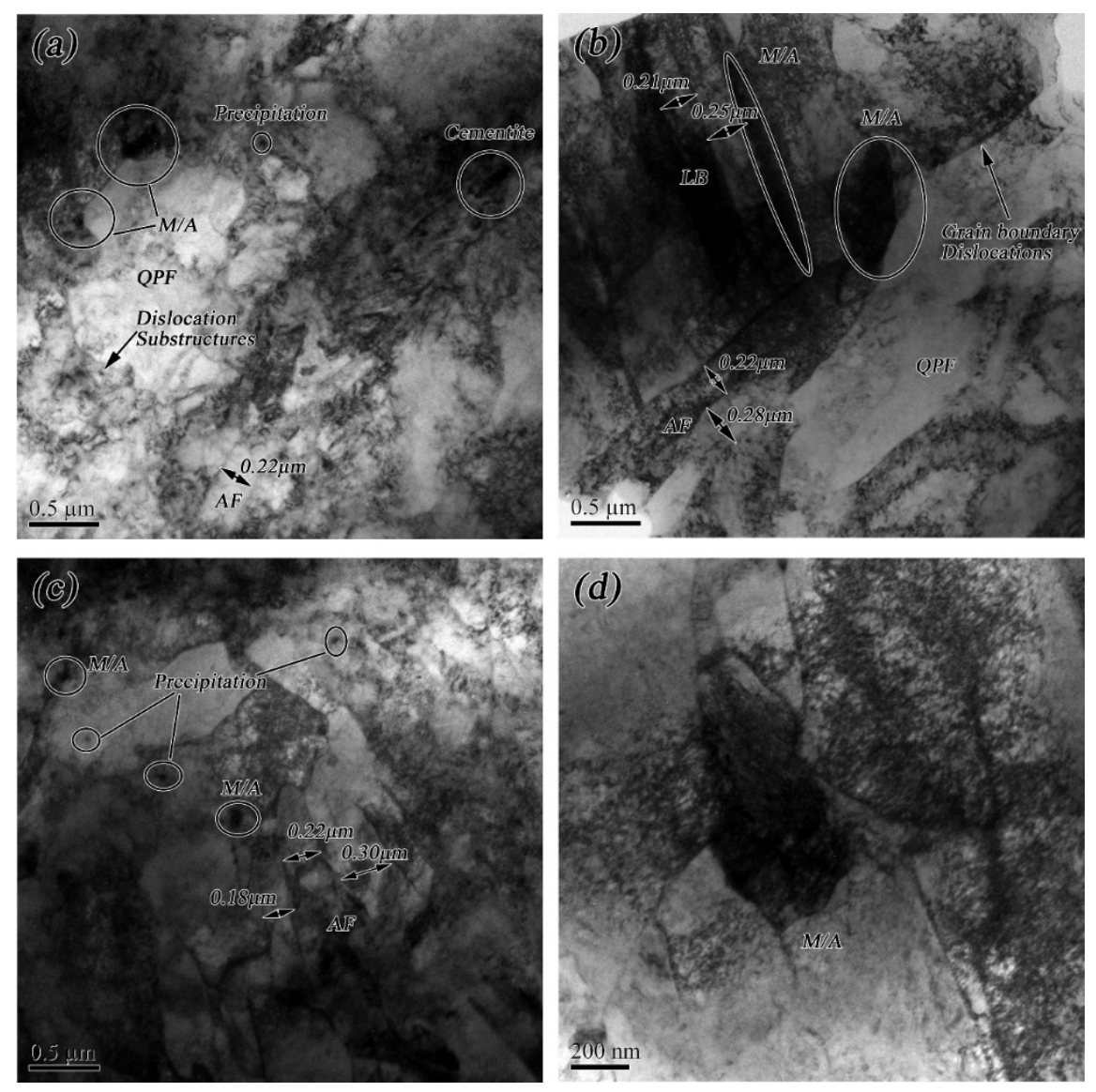

Fig. 4 TEM micrographs of API X90 pipeline steel: (a) dislocation substructure in QPF; (b) bainite laths; (c) acicular ferrite plates; (d) M/A constituent.

After hot induction bending, the microstructure of the outer arc side and the neutral axis of X90 bend under TEM are shown in Fig. 5 and Fig. 6, respectively. A high volume fraction of LB laths with misorientation were formed at the prior austenite grain boundaries, the laths width is about $0.53^{\sim} 1.34 \mu \mathrm{m}$. Moreover, some fine PF with the size of $0.31^{\sim} 0.65 \mu \mathrm{m}$ are observed in the outer arc side, as shown in Fig.5(a). Undecomposed carbides play an important role in strength improving, as shown in Fig. 5(b). A large number of dislocation cells and substructures can be observed in the PF grains, as shown in Fig. 5(c). Because of the effect of tensile stress on the outer arc side, a large number of dislocations formed in the deformed grains increasing the nucleation site of LB that could refine the grains. During the bending process, dislocations sliped to the grain boundaries and intertwined together to form dislocation cells or substructures eventually. Therefore, high density dislocations in the quenched microstructure, only amount of dislocations were eliminated after the high temperature tempering. The laths began to be widen and degenerated. The size of bainite laths in the outer arc side is $0.53^{\sim} 1.34 \mu \mathrm{m}$, as shown in Fig. 5(a). It is wider than that of the X90 parent pipe. The bainite microstructure still maintain the lath morphology due to the presence of carbide-forming elements such as Mo, Nb and Ti. Therefore, ensuring the high yield strength of $750 \mathrm{MPa}$, which is the highest in the bend zone. Dislocation cells and grain boundaries of laths could hinder the crack propagation and improve toughness. In general, the ability to prevent crack propagation is closely related to the size of the lath. The smaller lath, the better toughness. According to the TEM observation, two types of M/A constituents in the outer arc side: one is long strip distributed between bainite laths, and the other is blocky distributed between PFs or between ferrite and bainite boundaries. As shown in Fig. 5(d), M/A constituent with sharp morphology, it is prone to stress concentration when $\mathrm{M} / \mathrm{A}$ constituent is large in size and with angular, crack 
initiation and propagation that would detrimental to toughness [25].
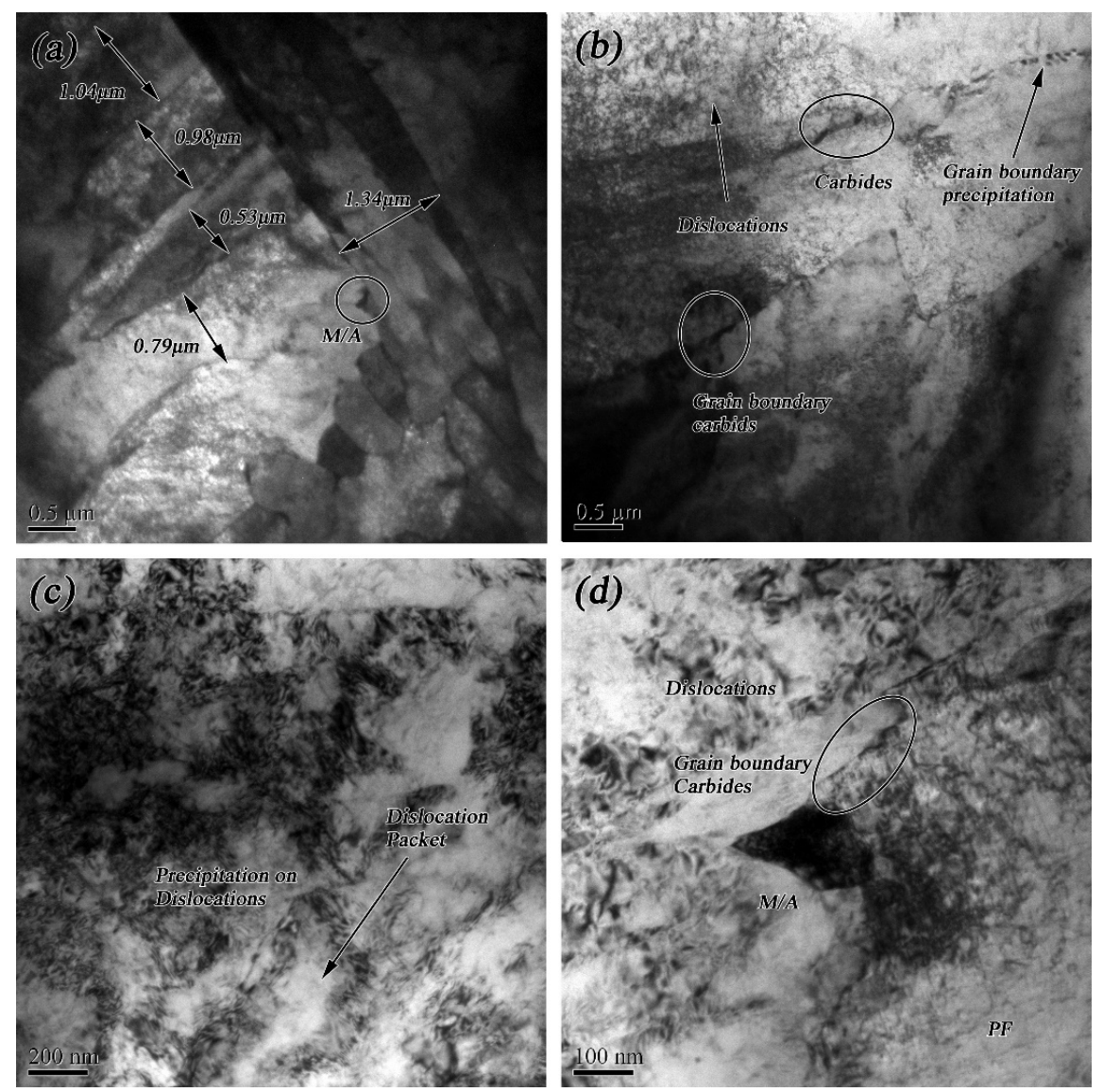

Fig. 5 TEM micrographs of the outer arc side in the X90 bend zone: (a) bainite laths; (b) carbides; (c) dislocation packets and precipitation on dislocations; (d) M/A constituent with angular.

The microstructure of the neutral axis position is composed of PF and GB. In Fig. 6(a), GB is composed of laths with a size of $0.24 \sim 1.04 \mu \mathrm{m}$. However, the length of bainite laths in GB is shorter than that of LB laths, and the characteristic of the laths is not as obvious as that in LB. M/A constituents are granular or equiaxed morphology distributed between the laths. Due to the short heating time during hot induction bending process, only a small amount of the original precipitates would dissolve that would lead to austenite composition non-uniformity and form the mix microstructure of GB and PF. Microalloying elements such as $\mathrm{Ti}, \mathrm{Nb}$ and $\mathrm{V}$, forming the fine carbide and carbonitride precipitates that could inhibit austenite grain growth and refine grains effectively [10]. M/A constituents decomposed after tempering at a high temperature, as shown in Fig. 6(d). In addition, a large number of dislocation tangles, dislocation cells and substructures still be observed in the position of the neutral axis to remain the high strength, as shown in Fig. 6(c). However, the dislocation density in PF is decreased compare with the outer arc side, as shown in Fig.6 (b, c), and the toughness improved. 

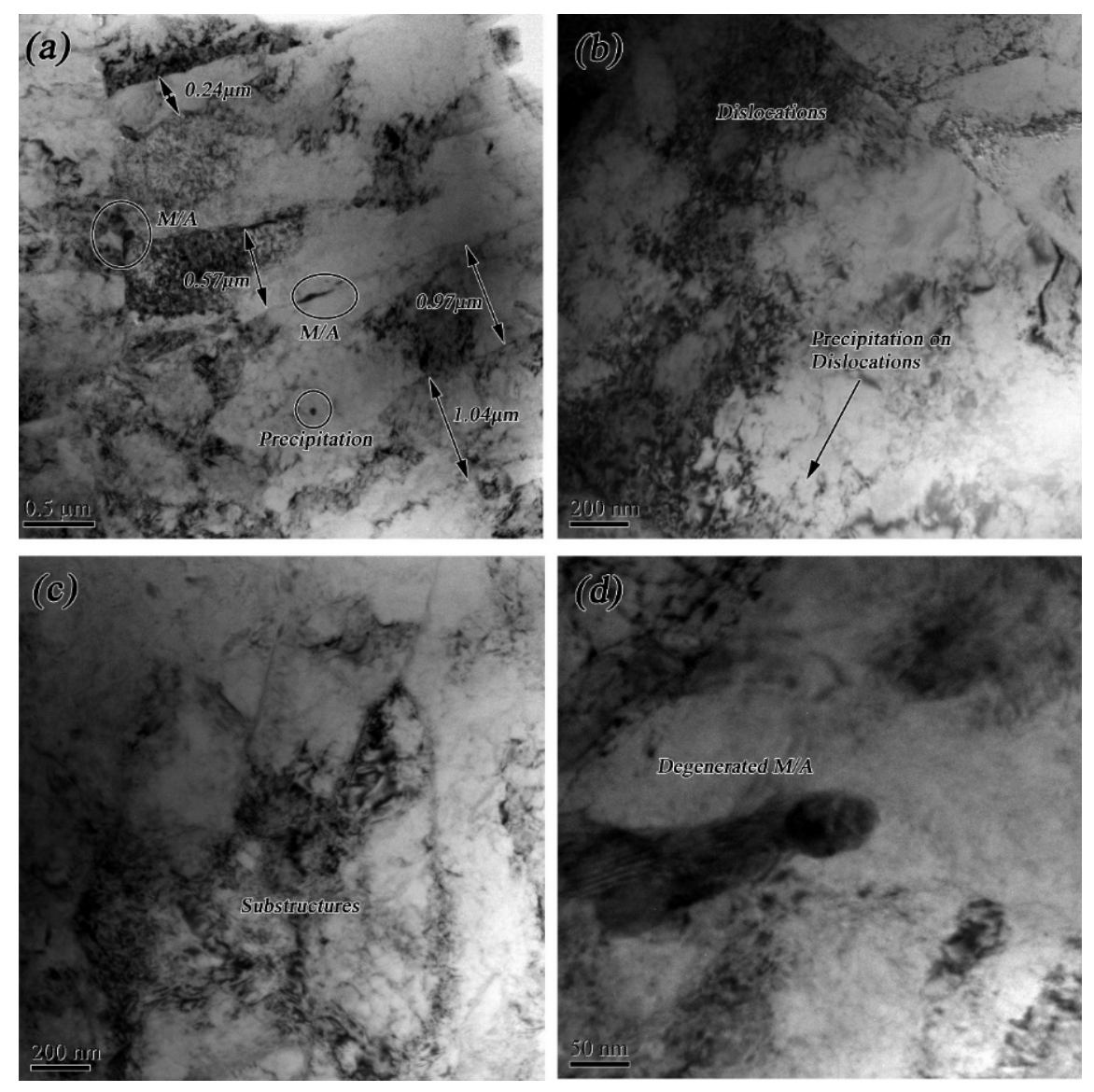

Fig.6 TEM micrographs of the neutral axis position in the X90 bend zone: (a) bainite laths; (b) precipitation on dislocations; (c) substructures; (d) degenerated M/A constituent.

\subsection{Results of precipitates}

X90 pipeline steel is rich in $\mathrm{Nb}$, Ti and other micro-alloying elements, there are a large number of microalloying elements precipitates. Fig.7 shows the precipitate characterizes of X90 pipeline steel. High content of microalloying elements promote to form precipitates and fine grains that play an important role in improving the strength and toughness combination. According to Fig. 7(a), some granular and elliptical precipitates distributed around the dislocation lines in the grains, and the size is range from $18.34 \mathrm{~nm}$ to $70.29 \mathrm{~nm}$. The precipitates of this size are mostly microalloyed elements $\mathrm{M}(\mathrm{CN})$ precipitated at a higher temperature during TMCP. The primary function of these precipitates is to obtain fine grains at room temperature by pinning grain boundaries and dislocations. In addition, there are some precipitates less than $15 \mathrm{~nm}$ in size, these precipitates are carbonitrides precipitated from supersaturated solid solution microalloying elements during the transformation of supercooled austenite to ferrite or cooled to single phase ferrite. In general, the volume fraction of these precipitates is very small, but play an effective role for strengthening. Especially the size of $2^{\sim} 5 \mathrm{~nm}$, mainly NbC [27]. It can also be observed from Fig. 7(a) that the dislocations disordered in the grain of QPF. The interaction between precipitates pinned to the dislocations and the tangle dislocations could decrease the distortion energy of austenite, delaying the recrystallization of austenite and forming fine grains at room temperature. 

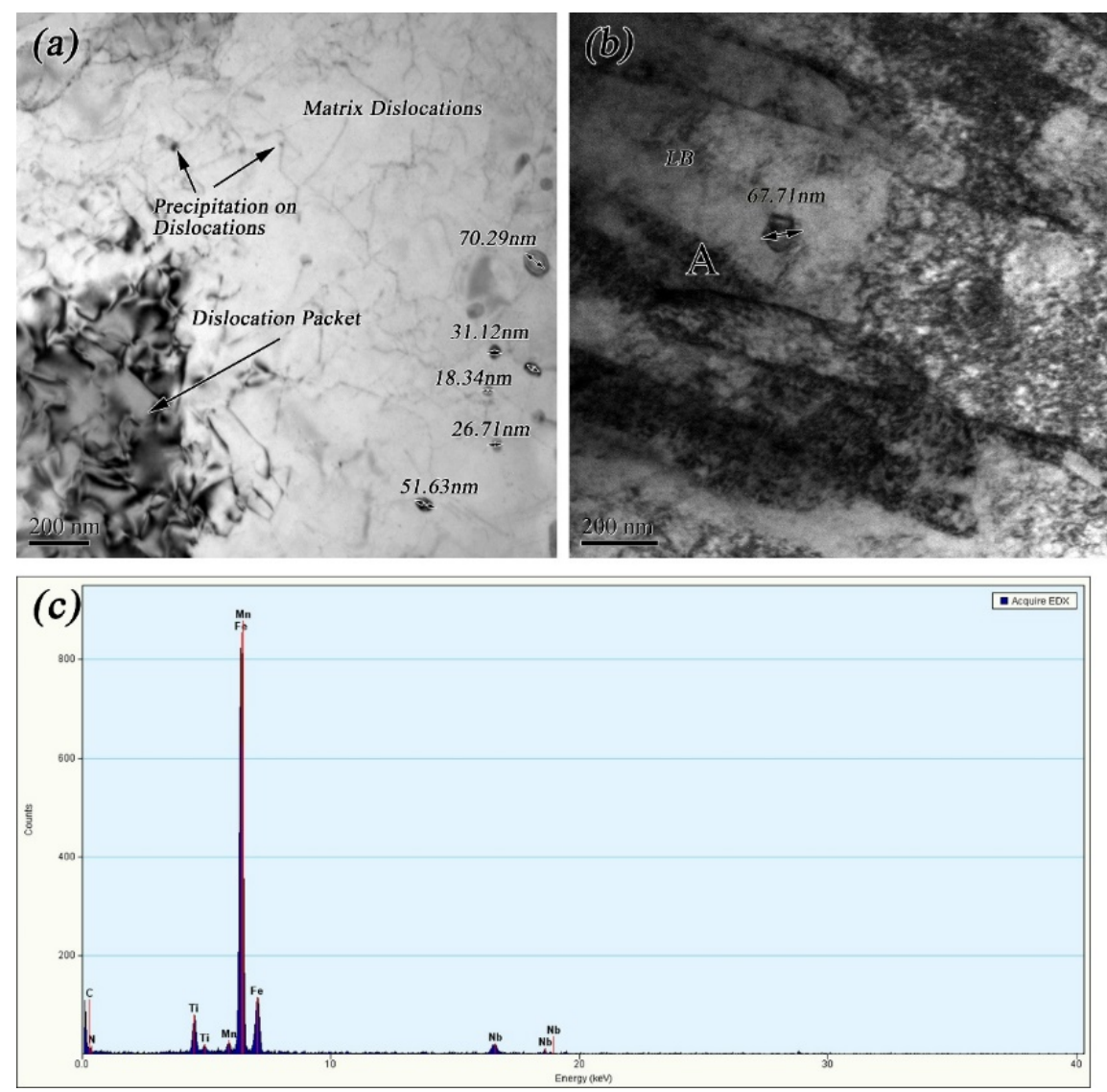

Fig. 7 TEM micrographs and the EDS result of precipitates of X90 pipeline steel: (a) precipitations and dislocations; (b) precipitations in the bainite laths; (c) EDS result of precipitate A.

In addition, according to Fig. 7(b), granular precipitate with a diameter of about $67.71 \mathrm{~nm}$ was observed in bainite lath. In order to verify its composition, transmission electron microscopy with EDS was used to analyze the composition. The result of EDS analysis is shown in Fig. 7(c). These granular precipitates are composed of $\mathrm{Nb}$ and $\mathrm{Ti}$ elements. Researchers $[1,28]$ found that it is common that complex Carbonitride ( $\mathrm{Ti}$, $\mathrm{Nb})(\mathrm{C}, \mathrm{N})$ in rich $\mathrm{Nb}$ and Ti microalloying steels. The core contains undissolved Ti-rich $(\mathrm{Ti}, \mathrm{Nb})(\mathrm{C}, \mathrm{N})$ and reheated residues, and the Nb-rich $(\mathrm{Nb}, \mathrm{Ti}) \mathrm{C}$ shell is formed at the post-precipitation stage. Undissolved $(\mathrm{Ti}, \mathrm{Nb})(\mathrm{C}, \mathrm{N})$ precipitation provides heterogeneous nucleation sites for $(\mathrm{Nb}, \mathrm{Ti}) \mathrm{C}$. EDS analysis of the precipitates in Fig. 7(c) shows that the $\mathrm{C}$ content of the composite precipitate is higher than that of $\mathrm{N}$. It indicated that the carbon-rich precipitates formed in the transformation zone of low temperature ferrite, promote AF nucleation sites in austenite grain, and segment the non-transformed austenite to refine grain.

TEM results of precipitates in the outer arc side and the neutral axis position are shown in Fig. 8. The fine precipitates are granular and ellipsoid morphology distributed on the matrix, as shown in Fig. 8(a) and Fig. $8(\mathrm{c})$. This kind of precipitate is mainly $\mathrm{NbC}$, and the main function is pin the sub-grain boundaries. In Fig. 8(a), a precipitate with a large size at the phase interface, the EDS results shown in Fig. 8(b). The main component of the precipitate is $\mathrm{NbC}$, with a small amount of $\mathrm{TiC}$, possibly (Ti, Nb) C. Fig. 8(d) shows the same results of precipitate $\mathrm{B}$. 

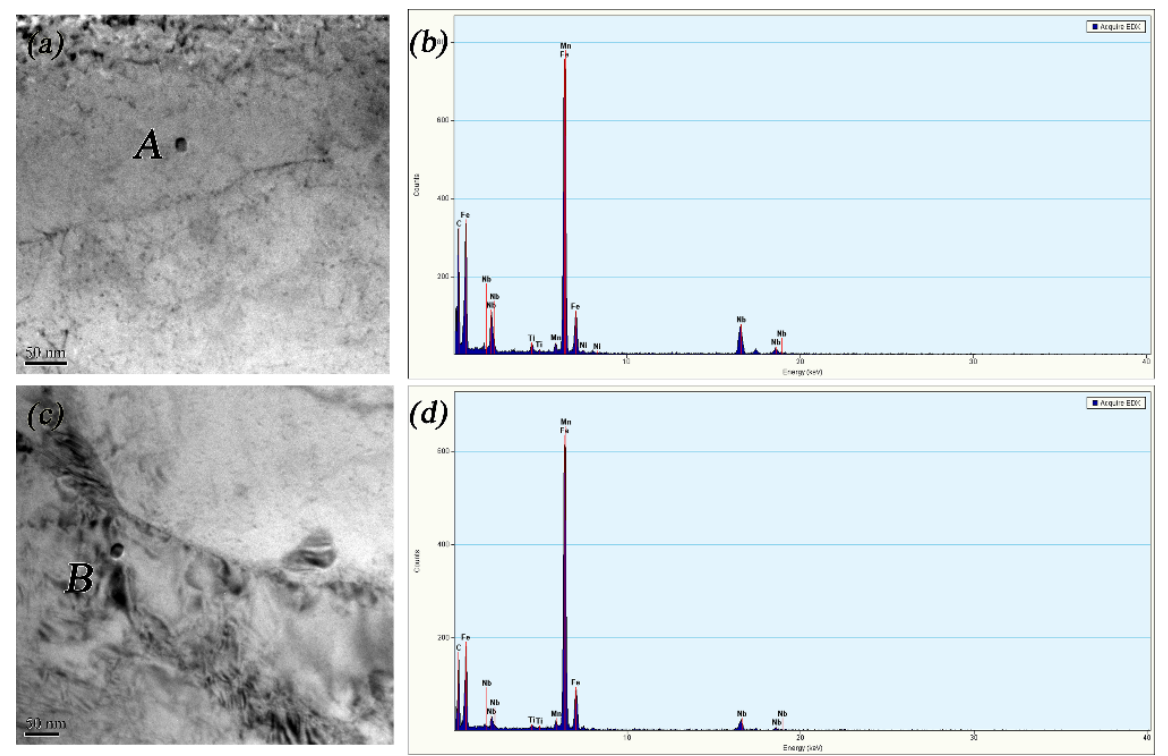

Fig. 8 The micrographs and EDS results of precipitates in the outer arc side and the neutral axis position: (a) micrograph of precipitate in the outer arc side; (b) EDS result of precipitate A; (c) micrograph of precipitate in the neutral axis position; (d) EDS result of precipitate B.

\section{4 grain boundaries distribution}

The grain boundaries distribution maps of X90 bend zone analyzed by EBSD are shown in Fig. 9. In the grain boundaries distribution maps, the black lines represent the high angle grain boundaries (HAGBs) that greater than $15^{\circ}$, and the red lines correspond to low angle grain boundaries (LAGBs) were characterized as boundaries with misorientation of $2^{\circ} \sim 15^{\circ}$. In the crystallographic theory, these two types of grain boundaries are usually used to represent the main grain boundaries. HAGBs are the grain boundaries of PF and LB. Moreover, some bainite packet boundaries can be regarded as $\Sigma 3\left(<111>/ 60^{\circ}\right)$ boundaries according to the typical Kurdjumov-Sachs (K-S) orientation relationship [29, 30]. Some sub-grain boundaries inside the $\mathrm{PF}$ are regarded as LAGBs. 

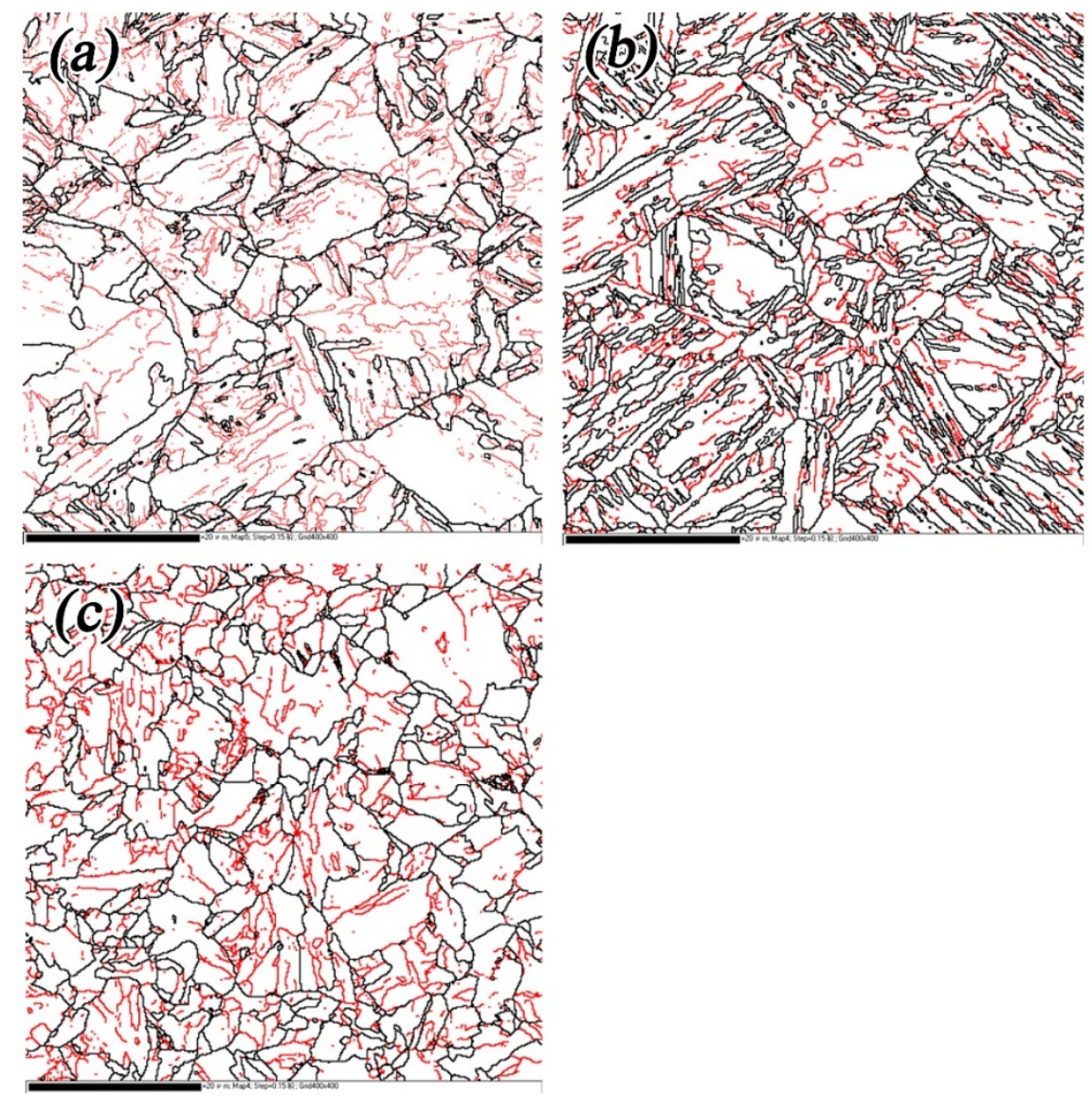

Fig. 9 Grain boundaries distribution of X90 bend, where black and red lines indicate the high misorientation angle boundaries $\left(\vartheta[?] 15^{\circ}\right)$ and low misorientation angle boundaries $\left(2^{\circ}[?] \vartheta[?] 15^{\circ}\right)$, respectively: (a) the inner arc side; (b) the outer arc side; (c) the neutral axis position.

Literatures $[27,31]$ reported that HAGBs can effectively contribute to higher cleavage microcrack resistance, the crack would be distorted when the tip encountered the HAGBs during the fracture process. A large number of HAGBs would consume a lot of energy when the crack torsion. On the contrary, the LAGBs have a less contribution on the crack torsional effect. During the bending process, the inner and outer arc side of the bend suffered stress effect. The relative frequency of HAGBs greater than $50^{\circ}$ on the inner arc side and the outer arc side is higher than the neutral axis position, as shown in Fig.10. The dislocations are transferred by the way of dislocation accumulation from the sub-grain boundaries to the grain boundaries in the deformed grains. The high density dislocations and sub-grain boundaries in the grains of the outer arc side are regarded as LAGBs, and the outer arc side have the highest strength because of the strengthening of dislocations and sub-grain boundaries is accompanied by fine grain strengthening [9]. According to the statistics of the results of EBSD, the relative frequency of LAGBs is $82 \%, 79 \%$, and $83 \%$ in the inner arc side, outer arc side and the neutral axis, respectively. The relative frequency of HAGBs is $18 \%, 21 \%$, and $17 \%$, respectively. The bend zone was subjected the double effect of heat treatment and deformation, and the bainite lath is accompanied by sub-grains (Fig. 5(a, b)). From the statistics data, the magnitude of LAGBs in the outer arc side is the lowest of the bend. In the grain boundaries theory, the outer arc side have the highest impact toughness. However, it is contrary to the actual toughness properties that the outer arc side has the lowest toughest, is $153 \mathrm{~J}$. Actually, a large number of LB with bainite laths in the outer arc side and it is believed that a crack could easily propagate along the bainite sheaves. In addition, some M/A constituents are sharp morphology existed in the outer arc side, it is detrimental to toughness. 
Fig.10 The misorientations distribution of the X90 bend.

\subsection{Local strain distribution by EBSD}

Kernel average misorientation (KAM) mapping approach can be used for visualizing of plastic deformation. Local misorientation was used to evaluate small local strain gradients in the material. Fig.11 shows the local misorientation distribution maps of X90 bend. The black lines represent grain boundaries. The local misorientation distribution maps represent the average misorientation between the given point and adjacent position in the same grain (usually less than $5^{\circ}$ ), mainly used to assess the small local strain gradient in the material $[33,34]$. Because of the formation of sub-grains with a displacive transformation in LB, and the misorientation gradient is significant, as shown in Fig.11(a, b). It is a very effective method to define the stress concentration through $0^{\circ} \sim 5^{\circ}$ misorientation. As shown in Fig.11, the misorientation of less than $1^{\circ}$ is indicated by blue, $1^{\circ} \sim 2^{\circ}$ is green, $2^{\circ} \sim 3^{\circ}$ is yellow, $3^{\circ} \sim 4^{\circ}$ is orange, and $4^{\circ} \sim 5^{\circ}$ is red. The results show that most of the area of the specimens is blue, that is, within the $0^{\circ}$ and $1^{\circ}$ local misorientation, corresponding to the ferrite region. The area represented by the yellow color is characterized by a strip-like distribution, as shown in Fig. 11(a, b), which is the result of the dislocation accumulation at the boundaries of the bainite laths. Zaefferer [35] indicated that volume expansion during bainite transformation process, resulting in shear stress and dislocation accumulation. It is also observed in Fig. 11(c) that since the dislocation is around the hard phase, the orange region appears at the boundaries of the equilibrium ferrite. During the deformation process, some micropores nucleate in the deep color zone firstly. In Fig. 11(b), the outer arc side of the bend have appeared a red area, which is a large local misorientation difference of $5^{\circ}$ that also verifies the fact that the outer arc side has the lowest toughness. 

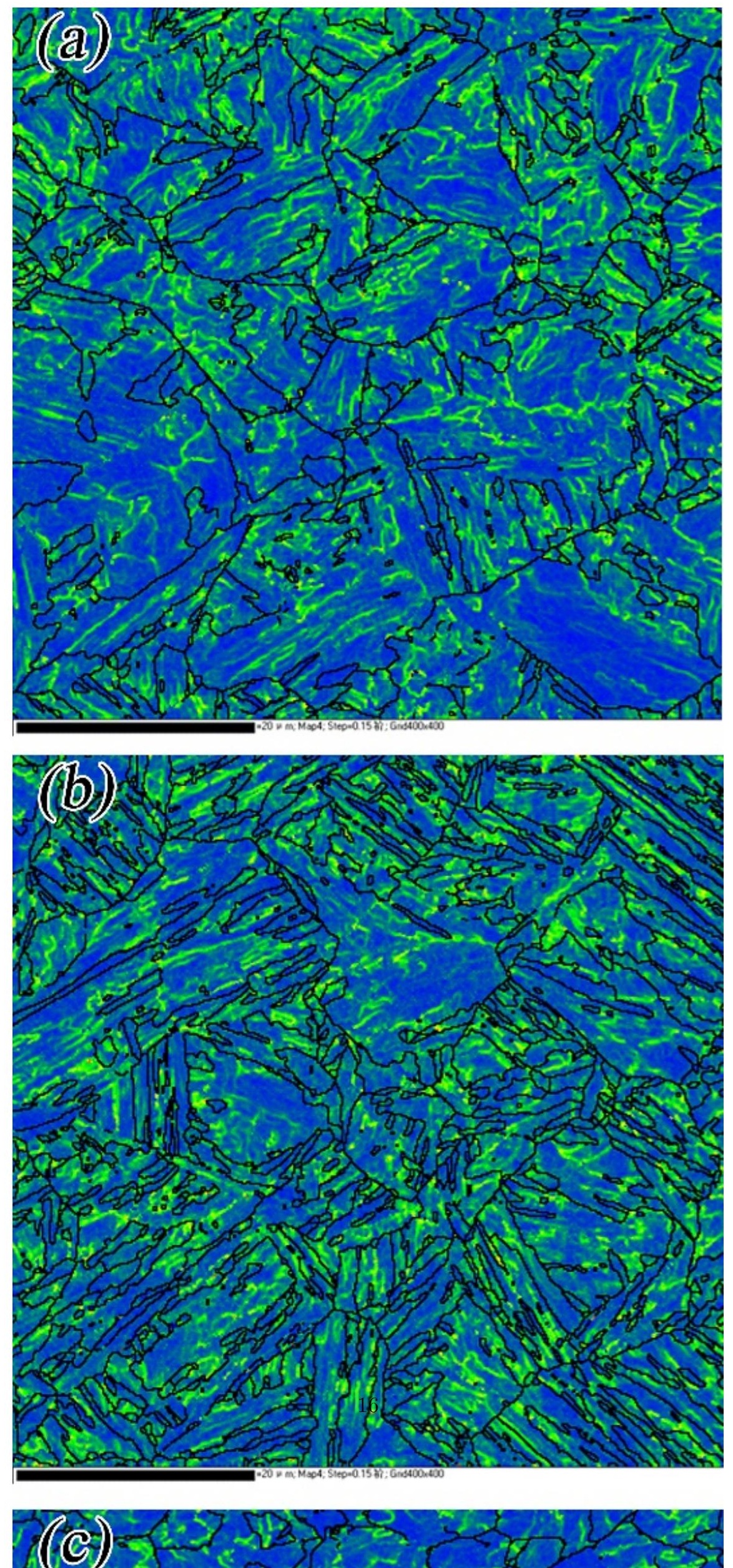
Fig. 11. Local misorientation distribution maps showing strain distribution of X90 bend: (a) inner arc side; (b) outer arc side; (c) the neutral axis position. The high angle grain boundaries are delineated in black lines.

Fig. 12 is a quantitative analysis of the strain distribution of the bcc matrix in the specimens. It can be seen from Fig. 12 that the local misorientation curve of the outer arc side is shifted right relative to the inner arc side and the neutral axis, and the local misorientation curve of the inner arc side is shifted right relative to the neutral axis. The average local misorientation of the inner arc side, the outer arc side and the neutral axis is $0.57^{\circ}, 0.62^{\circ}, 0.48^{\circ}$, respectively, which is consistent with the variation of the blue and yellow color areas in Fig. 12. According to the statistics of the average local misorientation, it can be confirmed that the outer arc side of bend suffered the largest strain, followed by the inner arc side, and finally the neutral axis position.

Fig.12 Change of local misorientation in the X90 bend

Conclusions

In the present study, effect of hot induction bending on the microstructure evolution in thick-walled X90 pipeline steel was studied. The major conclusions are derived as follows:

1. The strength of X90 bend decreased $30 \sim 80 \mathrm{MPa}$ compared to the X90 parent pipe, and the Charpy impact absorbed energy of X90 bend increased $20 \mathrm{~J}$ except for the outer arc side, which is the lowest, $153 \mathrm{~J}$.

2. The microstructure of X90 pipeline steel is consist of GB, AF, QPF and with a small amount of M/A constituents. After hot induction bending, the outer arc side in the X90 bend zone composed of a large number of LB and PF, and the inner arc side consist of GB, LB and PF, hardly observed AF in the bend zone. The position of the neutral axis is composed of GB and PF.

3. The width of bainite laths is about $0.2 \sim 0.3 \mu \mathrm{m}$ increased to $0.35^{\sim} 1.34 \mu \mathrm{m}$ in the outer arc side, and the width of laths is about $0.24^{\sim} 1.04 \mu \mathrm{m}$. The main component of the precipitate is NbC, with a small amount of $\mathrm{TiC}$, possibly ( $\mathrm{Ti}, \mathrm{Nb}) \mathrm{C}$.

4. LB, angular M/A constituents and the highest KAM value cause the worst impact toughness compared with the other specimens.

Acknowledgments

This study was funded by the open fund of State Key Laboratory of Oil and Gas Reservoir Geology Exploitation (Southwest Petroleum University) (PLN201730) and Nanchong City School Cooperation Project (18SXHZ0032).

Conflict of Interest Statement

The authors declare that they have no conflict of interest.

Data Availability Statement

All data generated or used during the study are inclued in the submitted article.

References

1. Hu J, Du LX, Xie H, et al (2014) Microstructure and mechanical properties of TMCP heavy plate microalloyed steel, Mater. Sci. Eng. A 607:122-131.

2. Hu J, Du LX, Wang JJ, et al (2013) Structure-mechanical property relationship in low carbon microalloyed steel plate processed using controlled rolling and two-stage continuous cooling, Mater. Sci. Eng. A 585:197-204.

3. Deardo A J (1995) Multi-phase Microstructures and Their Properties in High Strength Low Carbon Steels, ISIJ Int. 35:946-954.

4. W. C. Leslie (1981) The Physical Metallurgy of Steels, Mc Graw-Hill. 
5. Kang K, Kwon O, Lee W, et al (1997) Effect of precipitation on the recrystallization behavior of a $\mathrm{Nb}$ containing steel, Scr. Mater. 36(11):1303-1308.

6. I.Tamura, H.Sekine, T.Tanaka, C.Ouchi (1988) Thermomechanical Processing of HSLA Steels, Butterworth and Company, London.

7. Revilla C, López, B, Rodriguez-Ibabe J M (2014) Carbide size refinement by controlling the heating rate during induction tempering in a low alloy steel. Mater. Des. 62:296-304.

8. Wang X, Zhou J, Liang Q (2014) Multi-objective optimization of medium frequency induction heating process for large diameter pipe bending. Procedia. Eng. 81:2255-2260.

9. Silva R.A., Pinto A.L., Kuznetsov, A., Bott, I.S. (2018) Precipitation and grain size effects on the tensile strain-hardening exponents of an API X80 steel pipe after high-frequency hot-induction bending, Metals, 8:168.

10. T. Gladman (1997) Physical Metallurgy of Microalloyed Steels, Cambridge University Press, Cambridge.

11. Kim Y W, Song S W, Seo S J, et al (2013) Development of Ti and Mo micro-alloyed hot-rolled high strength sheet steel by controlling thermomechanical controlled processing schedule, Mater. Sci. Eng. A 565:430-438.

12. Bu FZ, Wang XM, Chen L, et al (2015) Influence of cooling rate on the precipitation behavior in $\mathrm{Ti}-\mathrm{Nb}-\mathrm{Mo}$ microalloyed steels during continuous cooling and relationship to strength, Mater. Charact. 102:146-155.

13. Sediako D (2012) Optimization of flow stress in cool deformed Nb-microalloyed steel by combining strain induced transformation of retained austenite, cooling rate and heat treatment, Acta Mater. 60:1221-1229.

14. Hu Z (1999) Computer simulation of pipe-bending processes with small bending radius using local induction heating, J. Mater. Process. Technol. 91:75-79.

15. Wang X, Xiao FR, Fu YH, et al (2011) Material development for grade X80 heavy-wall hot induction bends. Mater. Sci. Eng. A 530:539-547.

16. Ahn S T, Kim D S, Nam W J (2005) Microstructural evolution and mechanical properties of low alloy steel tempered by induction heating, J. Mater. Process. Technol. 160:54-58.

17. V. Sklenička, K. Kuchařová, P. Král, et al (2015) The effect of hot bending and thermal ageing on creep and microstructure evolution in thick-walled P92 steel pipe, Mater. Sci. Eng. A 644:297-309.

18. Wang X, Liao B, Da-Yong W U, et al (2014) Effects of hot bending parameters on microstructure and mechanical properties of weld metal for X80 hot bends, J Iron Steel Res. Int. 21:1129-1135.

19. Wang L, Wang B, Zhou P (2018) Misorientation, grain boundary, texture and recrystallization study in X90 hot bend related to mechanical properties, Mater. Sci. Eng. A 711:588-599.

20. Larzabal G., Isasti N., Rodriguez-Ibabe J.M. et al (2018) Precipitation Strengthening by Induction Treatment in High Strength Low Carbon Microalloyed Hot-Rolled Plates, Metall Mat Trans A 49:946961.

21. Zhou T, Yu H, Hu J, et al (2014) Study of microstructural evolution and strength-toughness mechanism of heavy-wall induction bend pipe. Mater. Sci. Eng. A 615:436-446.

22. Venkatsurya P K C, Jia Z, Misra R D K, et al (2012) Understanding mechanical property anisotropy in high strength niobium-microalloyed linepipe steels, Mater. Sci. Eng. A 556:194-210.

23. Jun H J, Kang J S, Seo D H, et al (2006) Effects of deformation and boron on microstructure and continuous cooling transformation in low carbon HSLA steels. Mater. Sci. Eng. A 442: 157-162.

24. Joo M S, Suh D W, Bae J H, et al (2012) Role of delamination and crystallography on anisotropy of Charpy toughness in API-X80 steel, Mater. Sci. Eng. A 546:314-322.

25. Wang C, Wu X, Liu J, et al (2006) Transmission electron microscopy of martensite- austenite islands in pipeline steel X70, Mater. Sci. Eng. A 438:267-271.

26. Yang G K, Hwang B, Lee S, et al (2005) Dynamic deformation and fracture behavior of ultrafine-grained aluminum alloy fabricates by equal-channel angular pressing, Metall. Mater. Trans. A 36:2947-2955.

27. Gleiter H (1971) The structure and properties of high-angle grain boundaries in metals, Phys. Status Solidi B 14: 9-38. 
28. Craven A J, He K, Garvie L A J, et al (2000) Complex heterogeneous precipitation in titanium-niobium microalloyed Al-killed HSLA steels-I. (Ti,Nb) $(\mathrm{C}, \mathrm{N})$ particles, Acta Mater. 48: 3857-3868.

29. Miyamoto G, Takayama N, Furuhara T (2012) Accurate measurement of the orientation relationship of lath martensite and bainite by electron backscatter diffraction analysis, Scripta Mater. 60:1113-1116.

30. Kitahara H, Ueji R, Tsuji N, et al (2006) Crystallographic features of lath martensite in low-carbon steel, Acta Mater. 54:1279-1288.

31. Zhang C, Wang Q, Ren J, et al (2012) Effect of martensitic morphology on mechanical properties of an as-quenched and tempered 25CrMo48V steel, Mater. Sci. Eng. A 534:339-346.

32. Wang X, Zhou J, Liang Q (2014) Multi-objective optimization of medium frequency induction heating process for large diameter pipe bending, Procedia Eng. 81:2255-2260.

33. Lee H W, Bae J H, Kim M S, et al (2011) Optimum design of pipe bending based on high- frequency induction heating using dynamic reverse moment, Int. J Precis. Eng. Man. 12:1051-1058.

34. Hu Z (2000) Elasto-plastic solutions for spring-back angle of pipe bending using local induction heating. J. Mater. Process. Technol, 102:103-108.

35. Zaefferer S, Ohlert J, Bleck W (2004) A study of microstructure, transformation mechanisms and correlation between microstructure and mechanical properties of a low alloyed TRIP steel, Acta Mater. $52: 2765-2778$. 